\title{
Management of diabetes during natural emergencies
}

\author{
Mintu Mani Baruah, K.V.S. Hari Kumar ${ }^{1}$ \\ Department of Medicine, Military Hospital, Durgmula, Jammu and Kashmir, ${ }^{1}$ Department of Endocrinology, Command Hospital, Chandimandir, \\ Haryana, India
}

\section{A B S T R A C T}

Disaster preparedness is an important but often a neglected part in the management of chronic disorders. India is facing an epidemic of diabetes and the patients with diabetes are also exposed to the risk of natural disaster along with other members of the society. India faced many disasters in the past including the Bhopal gas leak, Gujarat earthquake and Andaman tsunami. These disasters exposed the lacunae in the disaster preparedness and lead to devastating health consequences. Previous research focused more on the immediate, traumatic aspects of the disasters and neglected the impact on chronic disorders. The experience of managing diabetes after Hurricane Katrina gave important insights into the short and long term consequences of a disaster. Our article provides information about the impact of disasters on diabetes, difficulties in the management and suggested measures at various levels to improve the disaster preparedness.

Key words: Disaster preparedness, natural emergencies, type 2 diabetes

\section{INTRODUCTION}

India is facing an epidemic of diabetes and the estimated number of confirmed diabetes patients in India is 67 million. Another 30 million individuals are in the prediabetes group and by 2030, India will have the largest number of diabetes patients in the world. ${ }^{[1]}$ Diabetes is a chronic disorder characterized by hyperglycemia and is frequently associated with other metabolic abnormalities like hypertension and dyslipidemia. These disorders require regular medical therapy and disruption of such therapies can have serious consequences on health and economy in both the short term and long term. The large numbers of diabetes patients in the society expose them to the additional risk of natural disasters and weather emergencies as applicable to other population.

\begin{tabular}{|l|l|}
\hline \multicolumn{2}{|c|}{ Access this article online } \\
\hline Quick Response Code: & Website: \\
\hline & www.joshd.net \\
\hline & \\
\hline
\end{tabular}

A disaster is defined as an event that causes "disruption exceeding the adjustment capacity of the affected community". Disasters by their nature tend to be sudden in onset and independent of the control of individuals. A recent report from India suggest that more than $85 \%$ of disasters occur in the developing world but they contribute to less than $1 \%$ in the literature on the disaster related research. ${ }^{[2]}$ The disaster preparedness requires close interaction between individuals, community and administrative authorities at each level. Community resilience requires measures to protect and enhance the lives and assets during a stressful situation. ${ }^{[3]}$ Recent report after Mumbai terrorism attack highlights the resilience of the community as a critical measure to limit the damaging effect of the disaster. ${ }^{[4]}$ This involves strengthening the people to absorb all types of shocks and stresses and also develops a tailor made solution based on the understanding about the responses of these individuals.

People with chronic medical conditions that require daily medications are among the most vulnerable victims of natural disasters. This is because of the disruption in regular food intake, medical supplies and lack of health care facilities. People with diabetes can have serious impact of natural disaster owing to the additional risk factors like stress induced hyperglycemia, erratic meal timings

Corresponding Author: Dr. K.V.S. Hari Kumar, Department of Endocrinology, Command Hospital, Chandimandir, Haryana, India. E-mail: hariendo@rediffmail.com 
and proneness to infection as witnessed in the aftermath of Hurricane Katrina. ${ }^{[5-7]}$ The lack of proper medical records poses big problem for those in the shelters as the medications used have to be based on patient memory and knowledge. Individuals have to adjust to the replacement medicines available in the shelters which may not match to the exact schedule of the patient. Advanced planning is the key to tackle the natural disaster as the time available is very limited. We review the subject of diabetes disaster preparedness in this article and propose few guidelines for the help of people to plan ahead of time. The suggested diabetes disaster plan can be applied to all natural disasters like tsunami, earthquake, tornado and can be modified for all chronic medical conditions.

\section{Impact of natural disasters on diabetes}

Emergency situations occur worldwide and the damage caused by disasters seems to get worse. In a country like India with huge population and limited resources, the catastrophes create a situation where simple survival is a major concern. Despite the best planning, many aspects of the health care system are interrupted in a disaster. There are a limited number of studies available which explored the impact of natural disasters on diabetes.

Hurricane Katrina was the deadliest cyclone in the history of the United States. This cyclone occurred during August 2005 and was responsible for about 2000 fatal casualties and enormous damage to the health systems. An observational study involving 1,795 adults showed that the blood pressure, HbA1c and lipid parameters worsened after the Hurricane Katrina ${ }^{[8]}$ Another study suggested that $\mathrm{HbA1c}$, BP and LDL cholesterol showed significant patterns of change during the follow up period. ${ }^{[9]}$ An observational study involving 58 type 1 diabetes patients also suggested that the previous metabolic control is a predictor of subsequent control and the fear of hypoglycemia is a major risk factor for poor metabolic control. ${ }^{[10]}$ The disruption also extends to the clinical trials and the experience with the major trial ACCORD identified the difficulties in conducting the trial to maintain the patient follow up and scientific integrity of the trial after a disaster. ${ }^{[11]}$

\section{Diabetes disaster plan}

It is essential to be prepared, before a disaster is struck. The preparation is important at all levels of health care for the individual patient, health care workers and the administrative authorities. Hence, certain broad guidelines are required for the health care organizations, health care professionals, and people with chronic diseases like diabetes. A survey carried out to assess the emergency preparedness of families caring for type 1 diabetes patients revealed interesting findings. ${ }^{[12]}$ Most of the families had adequate medical supplies for 3 days and the families from higher socioeconomic strata were better equipped for an emergency. The emphasis is on better preparation at various levels of health care systems to tackle the diabetes in case of a natural disaster. Figure 1 describes the salient features of the diabetes disaster plan at the individual end and also the contents of the diabetes disaster kit and special advice for insulin requiring patients. All the patients are advised to have an individual plan, maintain an emergency kit and practice a family drill of emergency.

The enhanced state of preparation and responsiveness is also essential for health care workers and the administrators or policy makers. The key points highlighted by all the scientific societies are to identify the diabetes status of the patient, ensure adequate hydration, frequent checking of blood glucose, prevent hypoglycemia and ensure the intake of regular medications. American Diabetes Association (ADA) has constituted a disaster response task force for the recommendations on the subject after the experience with the Hurricane Katrina. ${ }^{[13,14]}$ The suggested recommendations in this article have been guided by the task force report.

\section{Indian scenario}

Despite falling prey to natural disasters like the 2001 Gujarat earthquake and the Tsunami in Andaman and Nicobar islands in 2004, India is still not prepared against any natural calamity. ${ }^{[15]}$ Realizing the importance of the subject, the government had set up a National Disaster Management Authority (NDMA) in 2005. The progress achieved by India

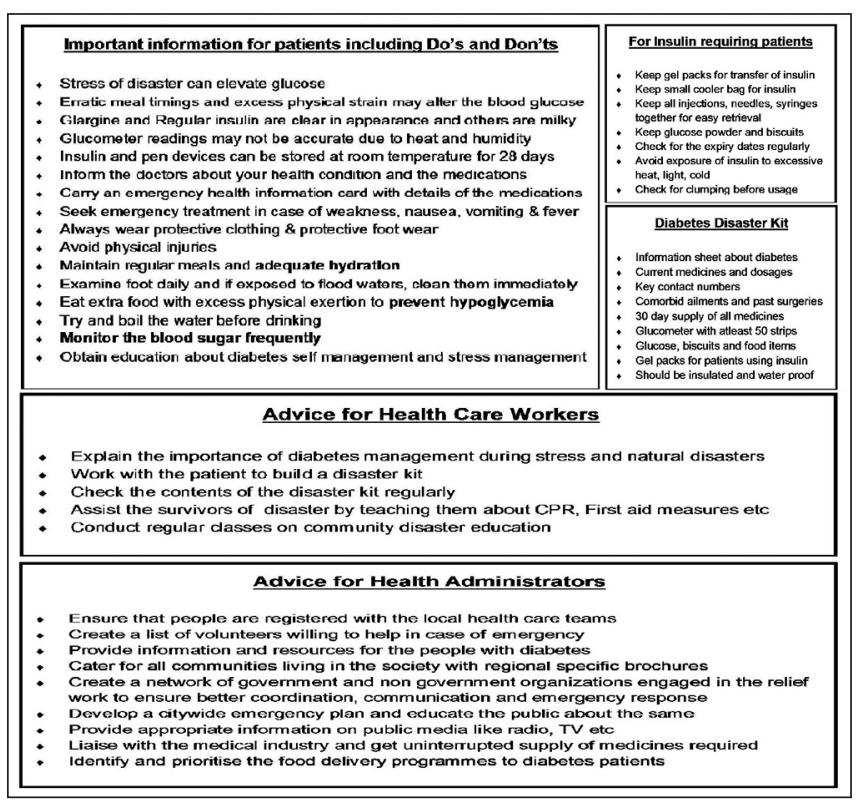

Figure 1: Diabetes disaster preparedness guidelines for Patients, Health Care Workers and Administrators 
is seen by the limited number of casualties after the massive evacuation efforts in the state of Orissa prior to cyclone Phailin. A population study from India has revealed higher prevalence of stress and hyperglycemia in patients affected by the tsunami. ${ }^{[16]}$ The clinical profile of hyperglycemic emergencies from the pilgrimage yatra to Amarnath shrine also revealed similar findings. ${ }^{[17]}$ High altitude, strenuous exertion, starvation and withdrawal of the existing drugs are the main contributors for the hyperglycaemic emergencies.

The authors had the first hand experience of managing the casualties after the Bhuj earthquake. The important problems identified in relation to the diabetes include lack of health information cards, stress induced hyperglycemia, mismatch between the medical supplies (insulin without syringes, $\mathrm{U}-100$ syringes with $40 \mathrm{IU} / \mathrm{ml}$ vial of insulin etc.), lack of cold chain facilities and supply of expired medicines. The other important problems are lack of awareness and education about the disease and medications, lack of facilities for regular monitoring and erratic food supplies to the hospital wards.

\section{CONCLUSION}

Every disaster is a learning experience and the same applies to the preparedness in case of diabetes also. Previous disasters like Gujarat earthquake, Hurricane Katrina and Cyclone Phailin have given us enough experience to handle a natural disaster. The patient education and physician participation are essential for good diabetes management during a natural disaster. The medical community should lead from the front in case of any natural disasters and help the policy makers in organizing the relief work. Logistic support and regular supply of the food material are the key areas of concern after a disaster. Disaster preparedness should be included in the medical teaching curriculum and also in the patient information leaflets.

\section{REFERENCES}

1. Anjana RM, Pradeepa R, Deepa M, Datta M, Sudha V, Unnikrishnan R, et al. ICMR-INDIAB Collaborative Study Group. Prevalence of diabetes and prediabetes (impaired fasting glucose and/or impaired glucose tolerance) in urban and rural India: phase I results of the Indian Council of Medical Research-India DIABetes (ICMR-INDIAB) study. Diabetologia 2011;54:3022-7.

2. Roy N, Thakkar P, Shah H. Developing-world disaster research: Present evidence and future priorities. Disaster Med Public Health Prep 2011;5:112-6.
3. Oxley MC. A "People-centred Principles-based" post-Hyogo framework to strengthen the resilience of nations and communities. Int J Disaster Risk Reduct 2013;4:1-9.

4. Roy N, Kapil V, Subbarao I, Ashkenazi I. Mass casualty response in the 2008 Mumbai terrorist attacks. Disaster Med Public Health Prep 2011;5:273-9.

5. Cefalu WT, Smith SR, Blonde L, Fonseca V. The Hurricane Katrina aftermath and its impact on diabetes care: Observations from "ground zero": Lessons in disaster preparedness of people with diabetes. Diabetes Care 2006;29:158-60.

6. Danna D, Bernard M, Schaubhut R, Mathews P. Experiences of nurse leaders surviving Hurricane Katrina, New Orleans, Louisiana, USA. Nurs Health Sci 2010;12:9-13.

7. Thethi TK, Yau CL, Shi L, Leger S, Nagireddy P, Waddadar $J$, et al. Time to recovery in diabetes and comorbidities following Hurricane Katrina. Disaster Med Public Health Prep 2010;4(Suppl 1):S33-8.

8. Fonseca VA, Smith H, Kuhadiya N, Leger SM, Yau CL, Reynolds K, et al. Impact of a natural disaster on diabetes: Exacerbation of disparities and long-term consequences. Diabetes Care 2009;32:1632-8.

9. Khoo TK, Smith SA. After Katrina: Quality of life among New Orleans residents with diabetes. Mayo Clin Proc 2008;83:601.

10. Kamps JL, Varela RE. Predictors of metabolic control in children with Type 1 diabetes: The impact of Hurricane Katrina in a prospective study. Diabetes Res Clin Pract 2010;88:234-41.

11. McDuffie R, Summerson J, Reilly P, Blackwell C, Goff D, Kimel AR, et al. The Action to Control Cardiovascular Risk in Diabetes (ACCORD) Trial and Hurricane Katrina: Lessons for managing clinical trials during and after a natural disaster. Contemp Clin Trials 2008;29:756-61.

12. Renukuntla VS, Hassan K, Wheat S, Heptulla RA. Disaster preparedness in pediatric type 1 diabetes mellitus. Pediatrics 2009;124:e973-7.

13. Arrieta MI, Foreman RD, Crook ED, Icenogle ML. Providing continuity of care for chronic diseases in the aftermath of Katrina: From field experience to policy recommendations. Disaster Med Public Health Prep 2009;3:174-82.

14. Disaster Response Task Force. American Diabetes Association Statement on Emergency and Disaster Preparedness: A report of the Disaster Response Task Force. Diabetes Care 2007;30:2395-8.

15. Agarwal SP. Health sector in India--progress, challenges and the way forward. J Indian Med Assoc 2005;103:692-8.

16. Ramachandran $A$, Snehalatha $C$, Yamuna $A$, Bhaskar $A D$, Simon M, Vijay V, et al. Stress and undetected hyperglycemia in southern Indian coastal population affected by tsunami. J Assoc Physicians India 2006;54:109-12.

17. Ganie MA, Koul S, Razvi HA, Laway BA, Zargar AH. Hyperglycemic emergencies in Indian patients with diabetes mellitus on pilgrimage to Amarnathji yatra. Indian $\mathrm{J}$ Endocrinol Metab 2012;16(Suppl 1):S87-90.

How to cite this article: Baruah MM, Kumar KH. Management of diabetes during natural emergencies. J Soc Health Diabetes 2014;2:67-9.

Source of Support: Nil. Conflict of Interest: None declared. 